\title{
A Discussion on the Relationship Between Fine Art Psychology and Fine Art Education From the Perspective of Modern Fine Art Education
}

\author{
Yue Huang \\ Yunnan College of Business Management; Kunming 650106 China
}

Keywords: Fine art education; fine art psychology; fine art in universities.

\begin{abstract}
Fine art education plays a role in promoting people's art quality and spiritual culture, while fine art psychology is a unique method born in the practice of art education. Therefore, fine art psychology is of great significance for improving fine art education and the two complement each other, which is of great value for training the professional quality and personality of students majoring in art. From the perspective of modern fine art education, the author analyzes and discusses the relationship between fine art psychology and fine art education, discloses the role of fine art psychology in promoting fine art education and fine art creation, which can help students of related majors form good art professional cognition and thinking ability, with the final purpose of forming a better theoretical guide for the development of fine art education in colleges and universities through this study.
\end{abstract}

\section{Introduction}

Fine art psychology, as an important discipline in fine art education, has not been attached much importance in the modern fine art education system, and the absence of fine art psychology has caused some problems in the value and future development of fine art education. To integrate the theoretical content of fine art psychology and its development situation can make clear the important role that it plays in the psychological function of fine arts, the formal structure of art works, the perfection of fine art education value and the artistic demand. It is useful to consider and discuss the unique value of fine art psychology education at the realistic level with the concept of modern fine art education. Therefore, it is also a theory needing being highlighted and treated properly in the development of modern fine art education, because the comprehensive elaboration and systematic analysis will help to achieve the good result of fine art psychology driving the development of fine art education.

\section{The Theory of Fine Art Psychology and the Development of Modern Fine Art Education}

\subsection{The Theory of Fine Art Psychology}

Fine art psychology is a science which studies art works and human psychology, and is also the knowledge helping people learn fine art better. So it is more inseparable from fine art education. At the same time, art psychology is a branch of educational psychology and a kind of knowledge that is practical and full of application. It has benefited from the brilliant achievements of European psychological research and continued to develop in combination with the educational factors of modern social psychology. With the continuous development of research on art, there gradually is some analysis about the impact of cognition and emotion on fine arts and education, which reflects the research on the scope of fine art psychology. With the passage of time, the study of fine art psychology has been on the way of systematic development. As a kind of modeling fine art psychology developed from the initial experimental aesthetics, it has become the predecessor of the development of modern fine art psychology. The establishment of fine art psychology is mainly based on the modeling art and the information communication form of a specific group. It can perfect the artistic thinking by grasping the law of aesthetic subjects' psychological activities in aesthetic activities and promoting the training of their art skills. At the same time, fine art psychology also aims at studying the emotion and consciousness of artists in their works, so as to realize the research and understanding of the specific aesthetic subject. 
That the fine art psychology can become an important branch of modern fine art education not only relies on its study of psychological behavior in the field of art, but can also be attributed to that it can guide the creative art practice more accurately, grasp the subtle relationship between art and psychology and thereby reflect the aesthetic trend and development of artistic style.

\subsection{Development of Modern Fine Art Education}

Art curriculum is an indispensable part of comprehensive quality education, and it is also a main way for students' aesthetic education and art ability training in higher education. Fine art education has an important position in the college art curriculum, and it is the stage for students to develop their basic aesthetic ability. Although fine art education has gradually become important and received extensive attention, the relevant teaching also shows the traditional aspect in colleges and universities .The curriculum setting cannot cultivate students' innovative consciousness, while the courses that teachers design cannot train the comprehensive ability of students. The art teaching plays a prominent role in cultivating students' cognitive ability and aesthetic ability [1].But now, the fine art education in colleges and universities lacks proper teaching methods and teaching theory, and related teaching projects also lack enough exercise to training students' core literacy. This is not consistent with the actual requirements for college art education and thus it should be highlighted and studied in reality.

With the continuous development of quality-oriented education and the progress of China's social education mode, the art education in modern colleges and universities has changed the inherent view that fine arts in a purely skilled discipline. After defining that fine art is the image art (namely the synthesis of visual aesthetic and artistic thinking), fine art teaching, as the basis and entry stage of art teaching, aims to cultivate students' practical ability and thinking ability of art, so that the teaching should focus on teaching ideas and methods.

\section{The Relationship Between Fine Art Education and Fine Art Psychology}

Art education is a great educational work. The purpose of fine art education is to cultivate students' ability of visual reading and expression, and guide them to describe and reflect on events in life, and ultimately help them learn how to analyze the world with image-based thinking. Image feeling is an important part of human cognitive model. Good image feeling can promote the overall development of people and help them form a good understanding of fine art. However, at present, the relationship between fine art education and fine art psychology has not been elaborated much in the higher education system, and thus it is more necessary to clarify the complementary relationship between the two.

\subsection{Fine Art Psychology Supports the Core Principle of Fine Art Education}

The object of the study of fine art psychology is the art discipline and the art, while art cannot be separated from the participation of people. At the same time, fine art is also the perceptual representation of the artistic people. The rich and colorful world comes from the ornament of colorful fine arts, while the colors and figures are collocated and tuned with the human consciousness. In the modern society, fine art education has been liberated from the concept of mechanical fine art and emphasized that the development of fine art should be achieved supported by the strength of human beings. At the same time, fine art is the art of human thinking and what it reflects is the inner world or sense of an independent individual[2].The way interpreting the art works has been combined with the natural and social concerns, not only comparing the differences in the painting style and painting school. This transformation embodies the role of fine art psychology as the subject of art cognition. The connotation of fine art education or works reflected in fine art psychology is its real value and expressive force. It reflects the self-transcendence achieved in the process of continuous development and integration between people and society. As a form of expression, fine art is only an objective presentation of the process. Therefore, fine art psychology reflects the core connotation of fine art education in reality, that is, it is needed to understand students' behaviors and subjects through fine art education to achieve the ultimate goal of art. 


\subsection{Fine Art Education Determines the Effect Level of Fine Art Psychology}

The artistic creation presents the perfect fit between external characteristics of the thing and spiritual experience of the individual. As mentioned above, the heartfelt artistic effect presented by art works is closely related to the rich life experience and thoughts of their creators. However, the own experience of creators cannot present lively and beautiful pictures, which reflects the role of fine art education. Fine art education is an education of basic knowledge and ability, as well as an enlightening and inspirational education. Successful fine art education must be able to make students realize their inner pursuit and have a strong desire to make their art work better. Art works are the intuitionistic embodiment of fine art education and fine art psychology. When interpreting a specific work or creator, the fine art education that the author accepted and the cognitive level of his aesthetic psychology are the important part of the study. Here takes the famous painter and artist Van Gogh as an example. His paintings still play a value-added role and are worth being collection after his death, because his unique artistic intuition and aesthetic experience, his good psychological atmosphere and perfect art expressive force had realized benign coexistence in his art life; that his artwork has become a major symbol of his personal and even modernist school of fine art can be attributable to his unique artistic orientation and sense of art [3].

To sum up, fine art education is the embodiment of fine art psychology to a large extent. If fine art psychology is divorced from fine art education, it is bound to not reflect its actual utility and cannot better express the practical value of art as a humanistic art.

\subsection{Fine Art Education and Fine Art Psychology Determine the Social Development of Individuals}

After the fine art education, students of art majors will form the professional thinking of art to a great extent and have certain artistic creative ability. But, diversification and interdisciplinary is the characteristics of the fine art development at present, which means that the art ability is only part of the comprehensive ability of students in relevant majors. It is this kind of diversification that makes the students have different future development. As far as the fine art major is concerned, there are great differences in the research and practice of the Chinese painting, oil painting and western painting. Furthermore, some emerging disciplines such as environmental art design and visual communication design also need the support of certain fine art quality. As the base, the teaching of drawing foundation should highlight the choice of individuals. Teachers should attach importance to the knowledge-based guidance and divergent thinking in the teaching process, emphasizing flexible knowledge. For example, the textbook and teaching cases can only inspire students' inspiration in the teaching of graphics and color. Teachers are expected to make good use of cases to expand students' thinking space, so as to make them understand what kind of graphics matching and color matching they will face in the future. Teachers should stick to the main position of "teaching", and meanwhile, they should be good at innovation and enlightenment. In this way, every student can master basic art knowledge through fine art courses and also have a clearer and more accurate understanding of the development direction of their major and career in the future.

\subsection{The Psychological Embodiment of Fine Art in Fine Art Education}

Fine art education is composed of two concepts, fine art and education. Fine art is a tool and also a means, and it provides the basic content of fine art education. Fine art, to a great extent, determines that the fine art psychology is different from other kinds of educational psychology [4]. Fine art psychology in fine art education reflects the influence of learning on psychological behaviors. Research and fine art knowledge learning are the main ways for students to contact aesthetic theories and aesthetic methods. However, the psychological differences are embodied by the different levels of learning strategies, learning skills, behavior patterns and cognitive styles that different students revealed in this process. The application of fine art psychology can correct students' bad habits and behaviors in the process of accepting art education and actively guide them to establish a good view of the world and nature. If the targeted cultivation is conducted according to the requirements of fine art education, students will gradually feel the lively nature in the process and then achieve the artistic presentation of activated aesthetics and rationality. 
At the same time, many aspects of fine art education involve fine art psychology. From the perspective of psychology, fine art education is a teaching form that follows the rule of human psychological activity. Therefore, only by creating a good atmosphere can the school provide students with learning conditions and spiritual affiliation more perfect, thereby achieving good mental health of students.

\section{How to Strengthen the Relationship Between Fine Art Education and Fine Art Psychology}

The innovation, namely combining fine art education with fine art psychology, is not only the modernization requirement of social science education concept nowadays, but also a specific affair of the conjoint analysis of fine art education and psychology. Strengthening the combination the two should be carried out from two aspects: theory and practice. On the one hand, researchers engaging in relevant theories need to carry out targeted research by taking into account the key points of conjoint development of fine art education and fine art psychology, forsake the aspects which lack psychological education and guidance in the traditional fine art education, and then realize the practical research and innovation which combines the two with new concepts. On the other hand, university teachers, as the front-line personnel of fine art education and fine art psychology teaching, should pay attention to innovation in teaching methods, so as to change the current demonstration mode into the mode of personally guiding students to practice this combination.

It is necessary to enhance teachers' concept that the fine art education should be combined with fine art psychology. As the ones who contact with students face to face, teachers' image and behaviors affect the students' psychology and thinking consciousness. The current college art teachers show the negative emotions and laziness to the combination of art education and art psychology. In view of this situation, training and counseling should be given actively to help the teachers have a better cognition of practical value of the combination of fine art education and fine art psychology to enhance the expressive ability and healthy ideological development of students. In this sense, the teachers can instill positive concept in daily teaching continuously to promote students to have a better understanding of art education and art psychology and study driven by inner desire. This has important significance for forming the idea of combining fine art education with fine art psychology.

\section{Conclusion}

To sum up, fine art education is a great educational work. Fine art education, on the one hand, is the continuation and development of art skills and knowledge to spread and develop human knowledge and spiritual wealth in reality, so as to satisfy the practical needs for material and spiritual in the modern society. At the same time, the role of fine art psychology in fine art education is a bilateral interaction. It mainly studies the process of human beings' fine art psychology, art creation, thinking activities (such as inspiration or perception) and psychology in the process of studying, so that they can have an overall perception of fine art education. The research in this paper can better clarify the relationship between fine art education and fine art psychology and the way of their conjoint development. It is believed that it will have important theoretical value for improving the modern fine art education system.

\section{References}

[1]. Li Qian. On the Importance and Practical Application of Visual Psychology in Fine Art Education for Kindergarten Teachers [J]. Art Education Research, 2016 (18): 136.

[2]. Li Xiupeng. A Discussion on the Application of Art Psychology in the Teaching of Art Appreciation [J]. Journal of Liaoning Higher Vocational, 2015,17 (02): 43-45.

[3]. Xie Nan. On the Relationship between Art Psychology and Art Education from the Perspective of Modern Art Education [D]. Xinjiang Normal University, 2013 
[4]. Wang Zhen. The Cultivation of the Teaching Ability of the Students Majoring in Fine Art Education in Changji University [J]. Popular Culture \&Arts, 2010 (24): 319. 